\title{
Study on the Technical Progress and Structure Optimization of Service Trade
}

\author{
Yongmei Zhang \\ Nanyang Institute of Technology, Nanyang, Henan, 473004
}

Keywords: Technical Progress, Structure Optimization, Service Trade

\begin{abstract}
Experiences in the development of world trade in services, especially in service-oriented countries, show that whether the structure of a country's trade in services is reasonable (optimization) is a key factor that affects the export competitiveness of service trade. Technological progress is an important factor that affects the structure of trade in services. The article starts from the correlation between technological progress and the structure optimization of service trade, and analyzes the significance of technological progress to the development of modern service industry and the economic principle that plays a role in the optimization of service structure from two aspects of theory and demonstration.
\end{abstract}

\section{Introduction}

Under the tide of globalization of service trade, although the service trade in our country has made great development, it obviously lags behind the trade in goods and has a long history of deficit. The service trade structure is irrational. In the world service trade division system, China's service trade The export structure is mainly labor-intensive service products with low added value. The import structure is dominated by high value-added human capital or capital-intensive service products, which is closely related to the unreasonable industrial structure and employment structure in China's service industries. In the future, with the diversification and concealment of market access restrictions of trade partners, the export of labor-intensive service products in our country is struggling. With the rapid development of China's trade in goods and the expansion of demand for modern services, China's demand for high value-added human capital or capital-intensive service products will continue to grow. This poses a challenge to our service industry in participating in international market competition after China's accession to the WTO. It also means that in the coming years, on the one hand, our country should pass the active Participate in the negotiation of world trade in services, create favorable external conditions for China's service industry to participate in international competition, and on the other hand, strive to optimize the internal structure of service industry in our country and improve the overall modernization level. By summing up the success of the countries with more developed service industries in various countries of the world today Experience and at the same time combine with the current situation of service industry in our country to find an effective way to enhance the industrial structure and modernization of service industry in our country so as to optimize our service trade structure and participate in the international market competition and create favorable internal conditions. In contrast, the former is subject to many external factors under the current global environment in which new protectionism is on the rise, while the latter is more proactive.

\section{Characteristics of Service Trade Structure Optimization}

The trend of changes in the export structure of service industries and the differences in the export structure of service industries among different types of countries are related to the resource conditions of various countries. However, the impact of modern science and technology on the social and economic life of all countries is the fundamental reason for the change in the structure of service trade. Because the development of science and technology has greatly improved the 
efficiency of services and reduced the cost of transportation, transportation costs have dropped significantly as the total amount of goods increases. In the meantime, the substantial increase in the proportion of other services reflects the fact that knowledge, technology and capital In the international trade status, and this trend may continue. In addition, because most of the high-income countries are developed countries, they have more abundant technical knowledge elements than middle- and low-income countries, so exports of other service products take a comparative advantage.

Technological advances have transformed many "non-tradables" in the service area into "tradables." The transfer technology of modern telecom makes the classical service products not be stored and transport characteristics have undergone great changes, the constraints of time and space become smaller and smaller, so that many of the original production and consumption needs of simultaneous services Can realize the separation of production and consumption. Technological advances, especially advances in information technology, have also brought about many new service delivery methods, such as e-commerce and network services. Some service products even appear in the form of tangible products (such as students and software , Recordings, etc.). This virtually diminished the intangible characteristics of traditional services. In the past decade or so, many emerging service industries have been separated from manufacturing industries to form an independent service industry. Among them, the technology, information and knowledge-intensive service industries are the fastest growing and have become an important part of service exports. Moreover, most of the products in these modern services can be produced centrally and then passed on to the users through exchanges, breaking the trait of service offerings in the traditional notion of non-marketability. In addition, information technology not only makes the development of the world's service industry more and more scientific and technological, but also makes many traditional industries and traditional services armed by high-tech means. These services are also enhanced by professional services, information management and electronic commerce Service technology content and labor productivity, therefore, the traditional service areas not only to develop new products, but also improve product competitiveness.

From the service recipients, the traditional service industry is mainly targeted at end consumers, the value of which is mainly to provide the ultimate social consumption. Many sectors of the modern service sector are separated from the production of material goods and may be anywhere in the industry chain, not as downstream as traditional service industries. Its service object is mainly engaged in production activities of enterprises, its products are mostly an intermediate investment, its development and production of physical products are closely integrated, so producer services is its main form of development. With the improvement of people's living standards and the specialization of social production, the demand of consumers for goods has been constantly raised. The social production departments, especially multinational corporations, have paid more attention to certain professional services and the quality and efficiency of producer services Directly related to the quality of goods and services, prices, labor productivity and value added size. Therefore, producer services will become a core part of modern service industry.

Structural optimization of service trade is closely linked with technological progress. The level of technological progress affects the magnitude and speed of the optimization of service trade structure. Developed countries represented by the United States have been at the leading level in technological progress, and the extent and speed of the optimization of service trade structure are unmatched by developing countries In addition, individual developing countries or newly industrialized countries also play an important role in the export of some modern service sectors, owing to the advantages of some of their higher elements.

As the world economy enters the era of service economy, service trade has not only become an important part of a country's international trade, but also become an important measure of a country's international competitiveness. From the above analysis of the evolution of the structure of the world trade in services, we can see that in order for a country to gain a favorable position in the international market for trade in services, it is necessary to increase the total volume of exports of services and export more modern service industries with high technological knowledge so as to 
enhance the modern The share of service exports in the total export of services is one of the important characteristics of the optimization of service trade structure. As the saying goes, "trade is a flow and industry is the source." The structural optimization of a country's trade in services is an outward manifestation of its rational structure of service industries. A highly industrial structure is conducive to enhancing overall competitiveness and further economic development in a country. Therefore, economic development should include changes in economic growth and economic structure (industrial structure). Economic growth includes two ways: one is epitaxial expansion and the other is connotation expansion. In comparison, the former is extensive growth based solely on factor input while the latter relies on technological progress to improve physical production factors Quality, by increasing labor productivity and the intensive growth of the utilization of the means of production.

\section{Accelerate technological progress and promote the optimization of service trade structure}

As a result of world science and technology revolution and the result of market economy development, economic globalization has become an objective trend of history. Economic globalization has manifested itself as follows. With the deepening of the international division of labor and the adjustment of the world's industrial structure, world trade and cross-border investment Rapid development. With the continuous development of economic globalization, the information and modernization of the service industry in the world and the international division of labor and cooperation have gradually expanded from the traditional manufacturing sectors to the high-end aspects of productive services and the global economy is constantly being transformed into a service economy. Therefore, the globalization of the service industry is The main symbol of economic globalization entering a new phase. The developed countries have gradually entered the era of service economy since the 1960s and the United States took the lead in transition to a service-oriented economy in the mid-1960s. Producer services have become the pillar industries in the developed countries. For example, the added value of the US producer services Accounting for more than $48 \%$ of its GDP, the situation in other developed countries are generally similar.

According to OECD (Organization for Economic Co-operation and Development), knowledge-based economy refers to the economy based on the production, distribution and use (consumption) of knowledge. It is a concept corresponding to the agricultural economy and the industrial economy and a new type of productive economy in the world today. In the knowledge-based economy, information technology and communication technologies are at the center of the knowledge-based economy and are the fastest growing sectors. Services play a major role in the knowledge-based economy. The emphasis of economy shifts from manufacturing to service industries. Talent factors And the level of skills and qualifications as a prerequisite for the realization of a knowledge-based economy. This shows that the knowledge economy is the ideal destination for the global economy. Moreover, the characteristics that a knowledge economy possesses are just the best conditions for developing a modern service industry. Because the development of modern service industry is based on information technology, human capital is an indispensable factor in the development of modern service industry. It is the new value orientation of knowledge-based economy that "respect knowledge and respect talent". Of course, with the progress of science and technology and the improvement of social productive forces, there is a gradual process of development of knowledge-based economy from scratch, from small to large, within the scope of a country or region. Mentioned earlier, the development of the knowledge economy in the United States is exactly the product of its social and economic development to a certain stage. India, by virtue of its abundant human capital elements, is also developing a knowledge-based economy. The modern service industries in these two countries all have strong competitiveness in international market competition. Developing a knowledge-based economy will be more beneficial to the modern service industries in these two countries development of.

The new globalization trend of service industry not only poses challenges to the development of China's service industry, but also challenges China's economic growth mode and industry, technology and enterprise management mode. According to the research of relevant scholars in our 
country, the current economy of our country has ended the era of agricultural economy and is in the latter stage of industrial economy. Therefore, it is time for the knowledge economy to reach a certain scale and reach a certain quality. Our government should set up a Knowledge Economy Development Committee as soon as possible to formulate a medium and long-term strategic plan and plan of action for knowledge development. Because of the enormous impact of technological elements on the knowledge economy, we must give full play to the role of technological progress in economic development. By promoting the rational flow of technical elements and accelerating the industrialization of high-tech achievements, China should focus on the development of the information industry and other high-tech industries. Therefore, in order to meet the challenge of knowledge-based economy, it is necessary to vigorously develop the information industry and other high-tech industries based on our country's reality and promote the optimization and upgrading of the traditional service industry through technological progress, Combined with the needs of the international market and our own strength to develop some new service industries and improve the knowledge content and technical content of our products. Only in this way can the quality, grade and added value of China's export products be enhanced by using high-tech, industrialized knowledge and knowledge-based value to form a technological product with Chinese characteristics so as to further optimize the structure of China's export products and further Enhance the international competitiveness of China's export products and finally take the intensive development path of foreign trade.

\section{Conclusion}

After the accession to the WTO, we find that the optimization of service trade structure in our country is accelerating, but it is mainly concentrated in the traditional service sectors. It is found that technology imitation has a positive correlation with the optimization of China's service trade structure, but the correlation coefficient is less than that of India. At the same time, Seriously inadequate. Combined with the experience of the United States and India, the article proposes that technological progress in service industry in our country still needs to imitate technology for a long period of time, but we must continuously improve the technology imitation ability to create favorable conditions for technological innovation.

\section{Acknowledgements}

Fund Project: Humanities and Social Sciences Research Project of Henan Provincial Department of Education, "Empirical Study on Factors Influencing Utilization of FDI in Producer Services in Henan Province" (2016-qn-207)

\section{References}

[1] Yuan Qi, Liu Chongyi. Changes in the US Industrial Structure and Development of Services [J]. World Economic Research, 2007, (02): 57-63.

[2] Guan Xin. Characteristics and Prospects of the Development of the U.S. Information Service Industry [J] .Global Technology Economy Outlook, 1999, (12) .5-7.

[3] Jing Yuejun. Study on the evolution of post-war American industrial structure [D]. Jilin University, 2004.6.

[4] Cheng Dazhong. Governmental Behavior in American Service Trade and Its Enlightenment [J]. Economic Liberation, 2000, (1): 55-57.

[5] Yang Jun, Li Xiaoyu, Yang dust. Technology imitation, human capital accumulation and independent innovation Empirical analysis based on China's provincial panel data [J] .Financial Research, 2007 (5): 18-28.

[6] Hao Bing. On Strengthening Governmental Services in Services [J] .Journal of Wuhan University (Humanities Sciences), 2005, (2): 219-221. 